\title{
Clinic and Home-Based Behavioral Intervention for Obesity in Preschoolers: A Randomized Trial
}

\author{
Lori J. Stark, $\mathrm{PhD}^{1}$, Stephanie Spear Filigno, $\mathrm{PhD}^{1}$, Christopher Bolling, $\mathrm{MD}^{2}$, Megan B. Ratcliff, PhD, $\mathrm{MPH}^{3}$, \\ Jessica C. Kichler, PhD ${ }^{1}$, Shannon M. Robson, PhD, MPH, RD4, Stacey L. Simon, PhD ${ }^{5}$, Mary Beth McCullough, PhD \\ Lisa M. Clifford, $\mathrm{PhD}^{7}$, Cathleen Odar Stough, $\mathrm{PhD}^{8}$, Cynthia Zion, $\mathrm{BS}^{1}$, and Richard F. Ittenbach, $\mathrm{PhD}^{9}$
}

Objective To test the hypotheses that an innovative skills-based behavioral family clinic and home-based intervention ( $\mathrm{LAUNCH}$ ) would reduce body mass index z score (BMIz) compared with motivational interviewing and to standard care in preschool-aged children with obesity.

Study design Randomized controlled trial with children between the ages of 2 and 5 years above the $95^{\text {th }}$ percentile for body mass index for age and sex recruited from 27 pediatrician offices across 10 recruitment cycles between March 12, 2012 and June 8, 2015. Children were randomized to LAUNCH (an 18-session clinic and homebased behavioral intervention), motivational interviewing (delivered at the same frequency as LAUNCH), or standard care (no formal intervention). Weight and height were measured by assessors blinded to participant assignment. The primary outcome, BMIz at month 6 after adjusting for baseline BMIz, was tested separately comparing LAUNCH with motivational interviewing and LAUNCH with standard care using regression-based analysis of covariance models.

Results A total of 151 of the 167 children randomized met intent-to-treat criteria and $92 \%$ completed the study. Children were $76 \%$ White and $57 \%$ female, with an average age of 55 months and BMI percentile of 98.57, with no demographic differences between the groups. LAUNCH participants demonstrated a significantly greater decrease in BMIz (mean $=-0.32, \mathrm{SD}= \pm 0.33$ ) compared with motivational interviewing (mean $=-0.05, \mathrm{SD}= \pm 0.27$ ), $P<.001, \omega^{2}=0.74$ and compared with standard care (mean $\left.=-0.13, \mathrm{SD}= \pm 0.31\right), P<.004, \omega^{2}=0.75$.

Conclusions In preschool-age children, an intensive 6-month behavioral skills-based intervention is necessary to reduce obesity. (J Pediatr 2017; $\mathbf{\square}: \mathbf{\square}-\mathbf{\square} \mathbf{0})$.

Trial Registration Clinicaltrials.gov NCT01546727.

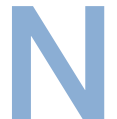

early 2 million preschool-aged children in the US meet criteria for obesity, ${ }^{1}$ yet there are few published treatment studies targeting this age group. ${ }^{2}$ Young children do not "outgrow" obesity. Obesity in the preschool years dramatically increases the risk of being overweight, obese, and even severely obese in later childhood and adulthood..$^{3-5}$ There is an association between early onset overweight and increased odds of developing diabetes ${ }^{6}$ and asthma. ${ }^{7}$ Efficacious treatment of obesity in the preschool years could dramatically change and even reverse this trend.

Despite the need for innovative weight management interventions for younger children, a recent review shows there are few randomized trials targeting weight reduction in preschoolers ${ }^{2}$ and only one, a pilot study, targeting preschoolers who are already obese. Focusing solely on children with obesity is important because they are at higher risk for mortality compared with overweight peers. ${ }^{8}$ This study examined a novel clinic and home family-based behavioral intervention (learning about activity and understanding nutrition for child health [LAUNCH] $),{ }^{9}$ designed to address specific behaviors caregivers report as barriers to establishing and maintaining healthy eating patterns in preschool children, ${ }^{10}$ including food neophobia and tantruming for food, through home visits designed to consolidate clinic-taught strategies into the home setting using in vivo practice of these skills. LAUNCH reduced body mass index (BMI) z score (BMIz) significantly more than 1 -session counseling by a pediatrician. ${ }^{9}$

\begin{tabular}{|ll|}
\hline AAP & American Academy of Pediatrics \\
AEs & Adverse events \\
BMI & Body mass index \\
BMIz & BMl z score \\
LAUNCH & Learning about Activity and Understanding Nutrition for Child Health \\
\hline
\end{tabular}

From the ${ }^{1}$ Department of Pediatrics, Division of Behavioral Medicine and Clinical Psychology, Cincinnati Children's Hospital Medical Center and University of Cincinnati College of Medicine, Cincinnati, $\mathrm{OH} ;{ }^{2}$ Pediatric Associates, PSC, Crestview Hills, KY; ${ }^{3}$ Independent Researcher, Atlanta, GA; ${ }^{4}$ Department of Behavioral Health and Nutrition, University of Delaware, Newark, DE; ${ }^{5}$ Department of Pediatrics, Division of Pulmonary Medicine, Children's Hospital Colorado, Aurora, CO; ${ }^{6}$ Department of Psychiatry and Human Behavior, Alpert Medical School of Brown University; ${ }^{7}$ Department of Clinical and Health Psychology, University of Florida Gainesville, FL; ${ }^{8}$ Department of Psychology, University of Cincinnati; and ${ }^{9}$ Department of Pediatrics, Division of Biostatistics and Epidemiology, Cincinnati Children's Hospital Medical Center and University of Cincinnati College of Medicine, Cincinnati, $\mathrm{OH}$

Supported by the National Institute of Diabetes and Digestive and Kidney Diseases (NIDDK) (R01DK091251), the National Center for Advancing Translational Sciences of the National Institutes of Health (NIH) (UL1 TR001425), and the NIH (T32 DK063929). An independent Data Safety and Monitoring Board participated in protocol review and provided study oversight. The authors declare no conflicts of interest.

0022-3476/\$ - see front matter. @ 2017 Elsevier Inc. All rights reserved.

https://doi.org10.1016/j.jpeds.2017.09.063 
Since the publication of the behavioral intervention for preschoolers with obesity, 2 additional studies were published targeting preschoolers above the 85 th percentile BMI in the primary care setting. A 6-month family-based behavioralintervention with 18 contacts was found to reduce overweight in this age group ${ }^{11}$ compared with an education only control, while in a separate study a 12-month, 7-session motivational interviewing intervention was not found to be more effective than usual care $^{12}$ in reducing BMI. motivational interviewing is one of the recommended treatment approaches by the American Academy of Pediatrics (AAP) Expert Committee on treatment of child and adolescent overweight/obesity ${ }^{13}$ and is designed to address barriers of motivation and ambivalence. As parents of preschoolers often do not recognize obesity ${ }^{14,15}$ and frequently feel it is unfair to implement changes to their child's diet, ${ }^{16}$ motivational interviewing is a credible alternative treatment, addressing parent ambivalence about implementing diet and activity changes for their child.

The objective of this phase III randomized clinical trial (ClinicalTrials.gov: NCT01546727) was to test whether the skills-based behavioral family clinic and home-based intervention $(\mathrm{LAUNCH})$ was superior to motivational interviewing and to standard care. It was hypothesized a priori that preschoolers receiving LAUNCH would have a greater decrease in their BMIz compared with motivational interviewing and standard care at post-treatment. Changes in parent BMI were examined secondarily.

\section{Methods}

Across 10 recruitment periods between March 12, 2012 and June 8, 2015, children and their families were recruited from 27 pediatric practices in the Greater Cincinnati/Northern Kentucky area. The study was approved by the institutional review board at the primary medical center where the study was conducted, and written informed consent was obtained from caregivers. Inclusion criteria were (1) ages 2-5 years; (2) BMI percentile for age and sex $\geq 95 \mathrm{th}^{17}$ but no more than $100 \%$ above the median BMI; (3) medical clearance from their pediatrician; (4) active patient with anthropometric measurements within the previous year; and (5) living within 50 miles from the medical center. Exclusion criteria included (1) developmental disability or medical conditions known to promote obesity (eg, Prader-Willi syndrome); (2) child enrolled in another weight control program; (3) taking weight-affecting medications (eg, steroids); (4) condition that would preclude full participation in the program; and (5) non-English-speaking.

Introductory letters were sent from the primary care practice with an "opt-out" postcard if families did not want to be contacted for the study. Families not returning the postcard were contacted by study staff. Seven additional practices, belonging to a unified health system whose administrative polices prevented participation in the recruitment procedures described above, were allowed to refer families to the study. Families meeting eligibility screening by phone and interest in study participation were scheduled for 2 baseline visits, at clinic and home. Children whose families did not complete both baseline visits were not randomized into the study. Intent to treat was defined a priori as being reached for treatment assignment (standard care) and attending the first intervention session (LAUNCH and motivational interviewing).

The study protocol is described in detail elsewhere. ${ }^{18}$ The randomization sequence was kept by the study statistician, concealed from study personnel, and was not assigned until all baseline measures were obtained from all children in a recruitment cycle. Child baseline BMIz was used as a stratification variable in a randomized stratification design with randomly chosen blocks of size 6 and 9, equal allocation to the 3 groups within blocks to ensure that BMIz was equivalent across the 3 arms. Beginning with cycle 8 , child race/ethnicity was added to the stratification process to ensure equivalence across the 3 arms.

The overall goal of LAUNCH and motivational interviewing was to follow the Expert Committee Recommendations on Prevention, Assessment and Treatment of Child and Adolescent Overweight and Obesity ${ }^{13}$ for reducing obesity in preschoolers by either stabilizing or slowing the rate of children's weight gain or to produce a gradual weight loss of $1 \mathrm{lb} /$ month. Both interventions targeted (1) limiting portion size; (2) limiting consumption of energy-dense foods; (3) limiting eating out; (4) consumption of $\geq 5$ servings of fruit and vegetables per day; (5) minimizing or eliminating sugarsweetened beverages; (6) limiting screen time to $\leq 2$ hours per day, and no TV in the room where child sleeps; and (7) achieving $\geq 1$ hour of moderate to vigorous physical activity per day. All families received $\$ 50$ for completing the baseline and 6-month assessments. Beginning at recruitment cycle 7 (where practices were farther from the medical center) families traveling $\geq 20$ miles were given an additional $\$ 25$ to help offset travel costs. Intervention arms are briefly described below and fully elsewhere. ${ }^{18}$

LAUNCH is an 18-session clinic and home family-based behavioral weight management intervention, consisting of a 3-month intensive treatment phase (weekly sessions) followed by a 3-month maintenance phase (every other week sessions). Intervention sessions alternated between clinic (10 sessions) and home (8 sessions) visits.

Parent clinic-based group sessions were 90 minutes each and led by a licensed clinical psychologist. Sessions consisted of education and problem-solving around parent and child diet, dietary and physical activity changes, and child behavior management strategies such as differential attention (eg, ignoring complaints about food, praising trying vegetables), contingency management (eg, rewarding healthy behaviors), limit setting, effective use of time-out to manage tantrums, shaping (eg, gradually introducing change), and exposure to introduce new foods, and implementing stimulus control measures to improve food choices and physical activity. Sessions 1-7 focused on dietary changes (with dietary tracking conducted throughout treatment), Sessions 8-10 focused on changing sedentary and physical activity, and sessions 11-18 focused on bringing all the skills together and problem-solving barriers to recommended lifestyle changes. A simultaneously held 
child group provided education about healthy eating, opportunities for moderate to vigorous physical activity, and exposure to a variety of fruits and vegetables through a meal. LAUNCH incorporated home visits (60 minutes) to facilitate generalization of the clinic taught skills to the home including parenting skills and changing the home environment ${ }^{19,20}$ using instruction, modeling and rehearsal of dietary, physical activity, parenting, and stimulus control techniques. Child groups and home visits were conducted by a postdoctoral fellow in clinical psychology or nutrition.

Motivational interviewing was a parent only intervention consisting of 18 sessions over 6 months, delivered weekly during the initial 3 months and every other week months 4-6. At the initial 60-minute session parents met with a pediatrician trained in motivational interviewing during which they completed questionnaires to assess their values and motivation for change, were given information about their child's weight and BMI percentile, and a packet of publicly available materials/brochures from the "Let's Go 5-2-1-0" program. Following the tenets of motivational interviewing, caregivers were asked about their concern about their preschoolers' weight, diet, and physical activity and asked about their desired child outcome, motivation, and confidence to make changes in any area of concern. If receptive, they were asked to select a nutrition or physical activity as a primary target of discussion from a menu of the AAP recommendations and the Let's Go 5-2-1-0 materials. Subsequent motivational interviewing intervention sessions were delivered by a licensed clinical psychologist trained in motivational interviewing in either the families' home (sessions $2,12,16)$ or over the telephone (14 sessions). These motivational interviewing intervention sessions consisted of a discussion of previous goals selected by the caregiver, exploration of the caregiver's perception of the success in reaching these goals, determination of caregiver's confidence and willingness to continue working on existing goal(s) or establishing new behavioral goals, and enhancement of motivation to address ambivalence and readiness to change behaviors in the caregivers, and identification of self-selected strategies for goal attainment. Following the tenets of motivational interviewing, the length of the phone sessions was determined by parents. The median phone session length was 15 minutes with $22 \%$ ( 135 of 625 of phone sessions) being $\leq 10$ minutes. All home visits were scheduled for 60 minutes.

Standard care informed caregivers of their child's weight status during the recruitment process, but neither the children nor caregivers received any treatment.

Caregivers completed a questionnaire regarding child date of birth, race, ethnicity, and sex as well as caregiver information on these variables and caregiver education, occupation, marital status, and family income. Caregivers' education and occupation were used to calculate a family's socioeconomic status using the Hollinghead 4-factor index of socioeconomic status ${ }^{21}$ where scores range from 8 to 66 with higher numbers indicating higher socioeconomic status.

Caregiver and children's weight and height were measured by trained personnel in the Clinical Translational Research Center Bionutrition Core who were unaware of participant treatment assignment using a standard protocol. ${ }^{18,22}$ The primary outcome was BMIz calculated using Centers for Disease Control and Prevention growth charts and the LMS method. ${ }^{23}$ In addition, BMI percentile, and percent over the 50th percentile $\mathrm{BMI}^{24}$ were calculated to assess eligibility.

All LAUNCH and motivational interviewing sessions were recorded, and 25\% were coded for treatment integrity. Attendance at treatment sessions was tracked for LAUNCH and motivational interviewing. Families were offered a make-up session prior to the next scheduled intervention session if a session was missed. A session was counted as complete if the family attended either session. Adverse events (AEs) were assessed at each intervention session (LAUNCH and motivational interviewing) and at 6 months (all groups) using a standardized protocol and AEs on child height were monitored as described elsewhere. ${ }^{18}$ Caregivers completed a checklist at the 6month assessment asking if they sought weight management advice from a healthcare professional (eg, physician, dietitian) for their preschooler outside of the study.

The primary goal of this trial was to determine if LAUNCH would lead to a greater reduction in BMIz at 6 months when compared with each of 2 comparisons: LAUNCH vs motivational interviewing and LAUNCH vs standard care. A priori power and sample size estimates indicated that we would be sufficiently powered $(80 \%)$ at 43 children per group using a longitudinal study design, an average expected effect size of $0.67 \sigma$ between groups, $\alpha_{2}=0.25$, and a $22 \%$ attrition rate. Primary analyses were performed using regression-based analysis of covariance models, with BMIz at 6 months serving as the outcome of interest, group assignment as the testable covariate, and BMIz at baseline as the adjusting covariate. Criteria for statistical significance included model and variable specific Wald statistics as well as $\omega^{2}$ and conditional error tests. With respect to model sensitivity, and as an added assurance that findings were stable irrespective of missing and/or extreme observations, all models were run with and without the extreme observations present, and using a series of 10 (multiple) imputations per model to estimate standard errors from the missing data (MIANALYZE procedure, SAS; SAS Institute, Cary, North Carolina). Because missing data were minimal (8\%) and all 3 scenarios produced the same pattern and magnitude of results within each hypothesis, a complete case analysis was deemed prudent and served as the basis for model results presented. All assumptions and distributional properties were tested and deemed amenable for parametric modeling. Both hypotheses were tested at an adjusted $\alpha=0.025$ level to account for multiplicity of comparisons. All data were analyzed using SAS v 9.3 (SAS Institute).

articipant flow through the trial appears in Figure 1 (available at www.jpeds.com). At baseline there were no statistically significant demographic differences between LAUNCH and motivational interviewing or standard care for child age, BMIz, BMI percentile, sex, race, ethnicity, family income, and Hollingshead score, all $P>$.05. Descriptive information for the 


\begin{tabular}{|c|c|c|c|c|}
\hline & $\begin{array}{l}\text { Overall } \\
(n=151)\end{array}$ & $\begin{array}{l}\text { LAUNCH } \\
(n=47)\end{array}$ & $\begin{array}{l}\text { Motivational interviewing } \\
\qquad(\mathrm{n}=50)\end{array}$ & $\begin{array}{c}\text { Standard care } \\
(n=54)\end{array}$ \\
\hline \multicolumn{5}{|l|}{ Child demographics } \\
\hline Age, $\mathrm{mo}^{\star}$ & $55.14(11.19)$ & $55.10(12.07)$ & $55.00(10.67)$ & $55.30(11.06)$ \\
\hline Sex (female) no. (\%)* & $86(56.95)$ & 25 (53.19) & $29(58.00)$ & $32(59.26)$ \\
\hline \multicolumn{5}{|l|}{ Race no. $(\%)^{\star}$} \\
\hline Black & $14(9.27)$ & $3(6.38)$ & $6(12.00)$ & $5(9.26)$ \\
\hline White & 115 (76.16) & 37 (78.72) & $38(76.00)$ & $40(74.07)$ \\
\hline More than 1/other & $22(14.57)$ & 7 (14.89) & $6(12.00)$ & 9 (16.67) \\
\hline \multicolumn{5}{|l|}{ Ethnicity no. $(\%)^{*}$} \\
\hline Hispanic or Latino & $9(5.96)$ & $1(2.13)$ & $3(6.00)$ & $5(9.26)$ \\
\hline Non-Hispanic & $142(94.04)$ & $46(97.87)$ & 47 (94.00) & $49(90.74)$ \\
\hline Weight, kg & 26.01 (5.52) & $26.15(6.16)$ & $25.91(5.02)$ & $25.97(5.47)$ \\
\hline Height, cm & $111.13(8.17)$ & $111.02(8.71)$ & $111.62(8.04)$ & 110.77 (7.92) \\
\hline Child BMIz* & $2.44(0.60)$ & $2.41(0.53)$ & $2.41(0.56)$ & $2.48(0.70)$ \\
\hline$\% \mathrm{OBMI}^{*}$ & $35.36(16.66)$ & 35.64 (17.21) & $34.18(15.77)$ & $36.21(17.23)$ \\
\hline Child BMI percentile* & $98.57(1.28)$ & $98.60(1.23)$ & 98.52 (1.31) & $98.57(1.30)$ \\
\hline \multicolumn{5}{|l|}{ Caregiver demographics } \\
\hline Age & $35.42(6.55)$ & $35.36(6.56)$ & 34.78 (5.95) & 36.07 (7.09) \\
\hline \multicolumn{5}{|l|}{ Relationship to child no. (\%) } \\
\hline Mother & $136(90.07)$ & $42(89.36)$ & $47(94.00)$ & $47(87.04)$ \\
\hline Father & $11(7.28)$ & $4(8.41)$ & $2(4.00)$ & $5(9.26)$ \\
\hline Grandparent & $3(1.99)$ & $1(2.13)$ & $1(2.00)$ & $1(1.85)$ \\
\hline Other & $1(0.66)$ & - & - & $1(1.85)$ \\
\hline \multicolumn{5}{|l|}{ Caregiver education no. (\%) } \\
\hline Less than high school degree & $2(1.32)$ & - & - & $2(3.70)$ \\
\hline High school graduate/GED & $16(10.60)$ & $5(10.64)$ & $5(10.00)$ & 6 (11.11) \\
\hline Some college/ specialized training & $53(35.10)$ & 21 (44.68) & $17(34.00)$ & 15 (27.78) \\
\hline College degree & 55 (36.42) & $15(31.91)$ & $20(40.00)$ & $20(37.04)$ \\
\hline Graduate degree & $25(16.56)$ & $6(12.77)$ & $8(16.00)$ & $11(20.37)$ \\
\hline \multicolumn{5}{|l|}{ Family income no. (\%)* } \\
\hline$<\$ 30 \mathrm{k}$ & $16(10.60)$ & $4(8.51)$ & $8(16.00)$ & $4(7.41)$ \\
\hline$\$ 30 \mathrm{k}-49.9 \mathrm{k}$ & $23(15.23)$ & 9 (19.15) & $5(10.00)$ & 9 (16.67) \\
\hline$\$ 50 k-99.9 k$ & $77(50.99)$ & 25 (53.19) & $23(46.00)$ & $29(53.70)$ \\
\hline$\geq \$ 100 k$ & 34 (22.52) & 9 (19.15) & $14(28.00)$ & $11(20.37)$ \\
\hline Not reported & $1(0.66)$ & - & - & $1(1.85)$ \\
\hline Hollingshead score* & $43.03(11.68)$ & $43.21(11.12)$ & $42.24(12.73)$ & 43.59 (11.31) \\
\hline \multicolumn{5}{|l|}{ Marital status no. (\%) } \\
\hline Single & $31(20.53)$ & $10(21.28)$ & $11(22.00)$ & 10 (18.52) \\
\hline Married & 108 (71.52) & $35(74.47)$ & $34(68.00)$ & 39 (72.22) \\
\hline Divorced & $6(3.97)$ & $2(4.26)$ & $2(4.00)$ & $2(3.70)$ \\
\hline Separated & $3(1.99)$ & - & $2(4.00)$ & $1(1.85)$ \\
\hline Widowed & $1(0.66)$ & - & $1(2.00)$ & - \\
\hline Cohabit, not married & $2(1.32)$ & - & - & $2(3.70)$ \\
\hline \multicolumn{5}{|l|}{ Caregiver weight status no. (\%) } \\
\hline Healthy weight (BMl<25) & $19(12.58)$ & $6(12.77)$ & $8(16.00)$ & $5(9.26)$ \\
\hline Overweight (BMI 25 to <30) & $25(16.56)$ & 7 (14.89) & $7(14.00)$ & $11(20.37)$ \\
\hline Obese (BMI $\geq 30)$ & 101 (66.89) & $33(70.21)$ & $32(64.00)$ & $36(66.67)$ \\
\hline Pregnant & $6(3.97)$ & $1(2.13)$ & $3(6.00)$ & $2(3.70)$ \\
\hline Self-reported prepregnancy BMI & $32.32(6.02)$ & $33.59(-)$ & $34.05(3.47)$ & $29.07(11.19)$ \\
\hline
\end{tabular}

GED, general educational development; \%OBMI, percent over the 50th percentile BMI.

${ }^{*}$ Denotes variables tested for differences at baseline, all $P^{\prime} \mathrm{S}>.05$.

sample as whole and by condition is shown in Table I. Across the whole sample, children were primarily white $(76.16 \%)$ and non-Hispanic $(94.04 \%)$ with a mean baseline BMIz of 2.44, corresponding to a BMI percentile of $98.57 \%$. Most of the caregivers were mothers $(90.07 \%)$ and met criteria for being obese $(66.89 \%)$ or overweight $(16.56 \%)$.

As shown in Figure 2, LAUNCH demonstrated a mean $( \pm$ SD) decrease in BMIz of $-0.32( \pm 0.33)$ while motivational interviewing yielded a decrease of $-0.05( \pm 0.27)$. LAUNCH participants had a statistically significant reduction in BMIz at the end of the intervention period compared with the motivational interviewing group, $P<.001$ (Table II).
Also shown in Figure 2, standard care yielded a decrease of $-0.13( \pm 0.31)$ compared with the mean decrease in BMIz of $-0.32( \pm 0.33)$ for LAUNCH. LAUNCH participants had a statistically significant reduction in BMIz at the end of the intervention period when compared with the standard care group, $P=.004$ (Table II).

As shown in Table III (available at www.jpeds.com), the decrease in BMIz was achieved in LAUNCH by a slowing in weight gain for children to an average gain of $0.67 \mathrm{~kg}$ over 6 months compared with motivational interviewing and standard care, both of which had an average weight gain of over $2 \mathrm{~kg}$. Children across groups had similar gains in height. This slowing 


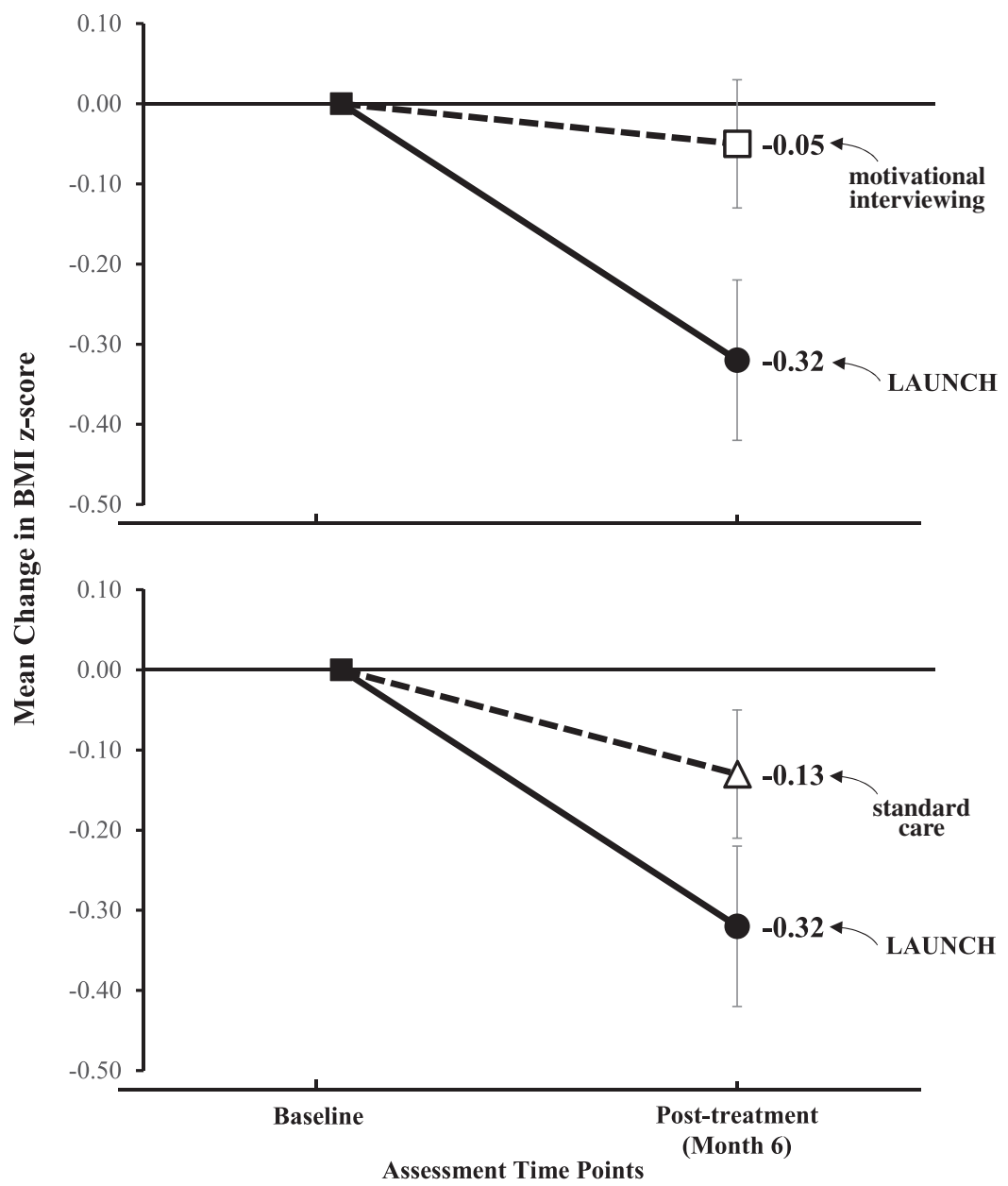

Figure 2. Mean change in BMIz for LAUNCH compared with motivational interviewing and standard care from baseline to posttreatment (month 6).

of weight gain while children grew in height resulted in an average BMI percentile change of -2.0 percentile points for LAUNCH, -0.21 for motivational interviewing, and -0.77 for standard care. Children in LAUNCH showed a decrease in percent over the 50 th percentile BMI of $-4.45 \%$, while motivational interviewing and standard care showed increases of $2.43 \%$ and $1.45 \%$, respectively.

Caregivers with a $\mathrm{BMI} \geq 25$, excluding those who were or became pregnant, underwent or were preparing for bariatric surgery, or lost to follow-up were analyzed $(n=109)$. A sig- nificantly greater reduction in BMI was also observed for parents in LAUNCH (mean $=-0.98, \mathrm{SD}=1.79$ ) compared with parents in motivational interviewing $($ mean $=0.43, \mathrm{SD}=1.63$, $\beta_{\text {Group }}=1.40[95 \%$ CI $\left.0.55,2.25] P=.002\right)$ and in standard care (mean $0.21, \mathrm{SD}=1.88, \beta$ Group $=1.17$ [95\% CI 0.32, 2.02] $P=.007)$.

LAUNCH demonstrated $96 \%$ adherence to the treatment manual checklist. For motivational interviewing all domain scores were above proficient thresholds as defined by the MITI fidelity scoring and 95\% motivational interviewing

Table II. Regression analyses comparing LAUNCH with motivational interviewing and with standard care

\begin{tabular}{|c|c|c|c|c|c|c|c|c|c|c|}
\hline \multirow[b]{2}{*}{ Variables } & \multicolumn{5}{|c|}{$\begin{array}{l}\text { LAUNCH vs motivational interviewing } \\
\qquad(\mathrm{N}=89)\end{array}$} & \multicolumn{5}{|c|}{$\begin{array}{l}\text { LAUNCH vs standard care } \\
\qquad(\mathrm{N}=93)\end{array}$} \\
\hline & $\begin{array}{c}\beta \\
\text { Coefficient }\end{array}$ & $95 \% \mathrm{Cl}$ & $\begin{array}{l}\text { Wald } \\
\text { statistic }\end{array}$ & $P$ value & $\begin{array}{c}\text { Effect size } \\
\left(\omega^{2}\right)\end{array}$ & $\begin{array}{c}\beta \\
\text { Coefficient }\end{array}$ & $95 \% \mathrm{CI}$ & $\begin{array}{l}\text { Wald } \\
\text { Statistic }\end{array}$ & $P$ value & $\begin{array}{l}\text { Effect } \\
\text { size }\left(\omega^{2}\right)\end{array}$ \\
\hline BMIz baseline & 0.89 & $-0.36,0.22$ & 15.53 & $<.001$ & & 0.91 & $0.80,1.02$ & 16.40 & $<.001$ & \\
\hline Intervention group & 0.27 & $0.15,0.40$ & 4.28 & $<.001$ & 0.74 & 0.19 & $0.06,0.32$ & 2.92 & $<.004$ & 0.75 \\
\hline Intercept & -0.07 & & & & & -0.10 & & & & \\
\hline
\end{tabular}

$95 \% \mathrm{Cl}$ of parameter estimates. 
adherent. LAUNCH participants attended an average 15.68 of 18 sessions ( $87 \%)$. Motivational interviewing participants attended an average 16.24 of 18 sessions (90\%). Two, 5, and 6 caregivers in LAUNCH, motivational interviewing, and standard care, respectively, reported consulting a healthcare professional for assistance in weight management for their preschooler outside of the study: child's pediatrician (LAUNCH 2; motivational interviewing 3; standard care 5), a dietitian (motivational interviewing 1; standard care 1), or both (motivational interviewing 1). There were no serious AEs in this study and no AE for child height. Only $1 \mathrm{AE}$, child bumping their head during a LAUNCH group activity, was coded as a "definitely" related, but mild and not requiring treatment.

\section{Discussion}

Results of this phase III randomized clinical trial demonstrated that the LAUNCH 18-session, skills-based behavioral family clinic and home-based intervention was effective in reducing child BMIz. We used a rigorous 3-group design that tested LAUNCH against a credible alternative treatment, motivational interviewing, that was delivered at the same frequency, but focused on motivation of the child's caregiver to make diet and activity changes and against a control group followed over the same 6- month period, but not assigned any treatment. The reduction in BMIz for LAUNCH participants was achieved primarily by slowing the rate of weight gain over the 6 months of intervention. Children in motivational interviewing and standard care gained almost triple the amount of weight during the 6-month period as children in LAUNCH. This slowing of weight gain resulted in a $4.45 \%$ decrease in percent overweight for $\mathrm{LAUNCH}$, while both motivational interviewing and standard care increased in their percent overweight by $2.43 \%$ and $1.45 \%$, respectively. Thus, the decrease in BMIz for LAUNCH was not only statistically significant, but clinically meaningful as well.

Our results add to the burgeoning treatment research in preschoolers ${ }^{11}$ and extend the findings with school age children, ${ }^{25}$ that intensive, skills-based behavioral treatment, such as LAUNCH, is necessary to reduce obesity at all ages. Our results are also consistent with Taveras et al and show that an motivational interviewing intervention that addresses motivation and resolution of ambivalence for parents about dietary change for their child is not sufficient to overcome the barriers parents face in terms of child behaviors to effectively implement dietary changes. ${ }^{12}$

Home visits in LAUNCH provided an opportunity for research staff to model and coach caregivers to effectively manage child behavior problems (eg, lengthy tantrums) via ignoring or time-out. Often times, caregivers inadvertently reinforced these behaviors by giving the child the requested food as a means of ending the tantrum. The home visits also provided dedicated time and personal guidance in helping parents identify "unhealthy" foods and making plans to remove them from the home, as well as incorporating exposure to new vegetables on a routine basis. Although home visits increase the cost of obesity treatment compared with clinic only, we have previously estimated that each home visit would cost $\$ 65.80$ if delivered by a social worker, resulting in a total estimated cost of $\$ 1276$ for the intervention. ${ }^{9}$ There is a growing interest in incorporating home visits into obesity treatment ${ }^{26}$ and prevention. ${ }^{27}$ Our results support this as a fruitful avenue for future obesity research as well.

Despite motivational interviewing being endorsed by the $\mathrm{AAP}^{13}$ for weight management, only 1 of 3 studies examining motivational interviewing for weight management in young children (those aged 4-8 and 2-8 years) ${ }^{12,28,29}$ found a significant effect for motivational interviewing on reducing BMI percentile. ${ }^{29}$ All studies of motivational interviewing with preschoolers, including the current study, used a combination of physicians and other healthcare professionals (dietitians, nurses, psychologists), a combination of in-person, but primarily phone based delivery, and sessions were brief (most reporting scheduled 15-minute phone sessions). The primary difference between the Resnicow et al study, where an intensive 10 -session motivational interviewing intervention was found to be superior to a 4-session physician only motivational interviewing intervention and care as usual, and other motivational interviewing studies, was that motivational interviewing was delivered over a 2-year intervention period compared with 6 months in the current study and Schwartz et al and 1-year in Taveras et al. ${ }^{12,28,29}$ This raises the possibility that the effects of motivational interviewing may be stronger if delivered over a longer period of time or take longer to manifest.

Although LAUNCH resulted in a statistical significantly greater reduction in BMIz than standard care and motivational interviewing, it was surprising that the standard care group showed a slight decrease in BMIz across the 6-month period. In our pilot study of $\mathrm{LAUNCH}$, the standard care group demonstrated an increase in $\mathrm{BMIz}^{9}$ whereas $\mathrm{LAUNCH}$ showed a decrease. This difference in the direction of change in the standard care group between the 2 studies could be a reflection of the societal emphasis on reducing obesity, which may also reflect why some families sought outside guidance on weight management during the course of the study.

Changing the diet and activity of preschool-age children to reduce obesity requires child behavior management skills training for parents. Targeting increasing parent motivation or overcoming ambivalence about dietary changes is not sufficient. Home visits appear to be an especially effective way to assist parents in the acquisition and generalization of these skills as they provide an opportunity for in vivo practice of these skills with supervision and modeling by interventionists in their home. Future research needs to test the intervention with a broader population sample and test models for dissemination.

We thank the 27 pediatric practices in Greater Cincinnati/Northern Kentucky for their enthusiastic and continuous collaboration. None of them received any compensation. We also thank the families who so generously gave of their time to participate in the study. We are grateful to our research personnel including Angela Combs, Jared Connor, and Megan Richardson. 
Submitted for publication Jun 25, 2017; last revision received Sep 7, 2017; accepted Sep 22, 2017

Reprint requests: Lori J. Stark, PhD, Division of Behavioral Medicine and Clinical Psychology, Cincinnati Children's Hospital Medical Center, 3333 Burnet Ave MLC 3015, Cincinnati, OH 45229. E-mail: Lori.Stark@cchmc.org

\section{References}

1. Ogden CL, Carroll MD, Lawman HG, Fryar CD, Kruszon-Moran D, Kit BK, et al. Trends in obesity prevalence among children and adolescents in the United States, 1988-1994 through 2013-2014. JAMA 2016;315:22929.

2. Foster BA, Farragher J, Parker P, Sosa ET. Treatment interventions for early childhood obesity: a systematic review. Acad Pediatr 2015;15:35361.

3. Cunningham SA, Kramer MR, Narayan KM. Incidence of childhood obesity in the United States. N Engl J Med 2014;370:403-11.

4. Guo SS, Wu W, Chumlea WC, Roche AF. Predicting overweight and obesity in adulthood from body mass index values in childhood and adolescence. Am J Clin Nutr 2002;76:653-8.

5. Nader PR, O’Brien M, Houts R, Bradley R, Belsky J, Crosnoe R, et al. Identifying risk for obesity in early childhood. Pediatrics 2006;118:e594-601.

6. Al Mamun A, Cramb SM, O’Callaghan MJ, Williams GM, Najman JM. Childhood overweight status predicts diabetes at age 21 years: a followup study. Obesity (Silver Spring) 2009;17:1255-61.

7. Mannino DM, Mott J, Ferdinands JM, Camargo CA, Friedman M, Greves $\mathrm{HM}$, et al. Boys with high body masses have an increased risk of developing asthma: findings from the National Longitudinal Survey of Youth (NLSY). Int J Obes (Lond) 2006;30:6-13.

8. Flegal KM, Kit BK, Orpana H, Graubard BI. Association of all-cause mortality with overweight and obesity using standard body mass index categories a systematic review and meta-analysis. JAMA 2013;309:71-82.

9. Stark LJ, Spear S, Boles R, Kuhl E, Ratcliff M, Scharf C, et al. A pilot randomized controlled trial of a clinic and home-based behavioral intervention to decrease obesity in preschoolers. Obesity (Silver Spring) 2011;19:134-41.

10. Bolling C, Crosby L, Boles R, Stark L. How pediatricians can improve diet and activity for overweight preschoolers: a qualitative study of parental attitudes. Acad Pediatr 2009;9:172-8.

11. Quattrin T, Roemmich JN, Paluch R, Yu J, Epstein LH, Ecker MA. Efficacy of family-based weight control program for preschool children in primary care. Pediatrics 2012;130:660-6.

12. Taveras EM, Gortmaker SL, Hohman KH, Horan CM, Kleinman KP, Mitchell K, et al. Randomized controlled trial to improve primary care to prevent and manage childhood obesity: the High Five for Kids study. Arch Pediatr Adolesc Med 2011;165:714-22.

13. Barlow SE, Committee. Expert committee recommendations regarding the prevention, assessment, and treatment of child and adolescent overweight and obesity: summary report. Pediatrics 2007;120(Suppl 4):S16492.

14. Duncan DT, Hansen AR, Wang W, Yan F, Zhang J. Change in misperception of child's body weight among parents of American preschool children. Child Obes 2015;11:384-93.
15. Garrett-Wright D. Parental perception of preschool child body weight. J Pediatr Nurs 2011;26:435-45.

16. Pagnini DL, Wilkenfeld RL, King LA, Booth ML, Booth SL. Mothers of pre-school children talk about childhood overweight and obesity: the weight of opinion study. J Paediatr Child Health 2007;43:806-10.

17. Kuczmarski RJ, Ogden CL, Grummer-Strawn LM, Flegal KM, Guo SS, Wei R, et al. CDC growth charts: United States advance data from vital and health statistics; no. 314. Hyattsville (MD): National Center for Health Statistics; 2000.

18. Stark LJ, Filigno SS, Bolling C, Ratcliff MB, Kichler JC, Robson SL, et al. Learning about Activity and Understanding Nutrition for Child Health (LAUNCH): rationale, design, and implementation of a randomized clinical trial of a family-based pediatric weight management program for preschoolers. Contemp Clin Trials 2017;52:10-9.

19. Brotman LM, Klein RG, Kamboukos D, Brown EJ, Coard SI, Sosinsky LS. Preventive intervention for urban, low-income preschoolers at familial risk for conduct problems: a randomized pilot study. J Clin Child Adolesc Psychol 2003;32:246-57.

20. Morgan WJ, Crain EF, Gruchalla RS, O'Connor GT, Kattan M, Evans R 3rd, et al. Results of a home-based environmental intervention among urban children with asthma. N Engl J Med 2004;351:1068-80.

21. Hollingshead AB. Four factor index of social status. New Haven (CT): Yale University; 1975.

22. Lohman TG, Roche AF, Martorell R. Anthropometric standardization reference manual. Champaign (IL): Human Kinetics Books; 1988.

23. Cole TJ, Bellizzi MC, Flegal KM, Dietz WH. Establishing a standard definition for child overweight and obesity worldwide: international survey. BMJ 2000;320:1240-3

24. Paluch RA, Epstein LH, Roemmich JN. Comparison of methods to evaluate changes in relative body mass index in pediatric weight control. Am J Hum Biol 2007;19:487-94.

25. O'Connor EA, Evans CV, Burda BU, Walsh ES, Eder M, Lozano P. Screening for obesity and intervention for weight management in children and adolescents: evidence report and systematic review for the US Preventive Services Task Force. JAMA 2017;317:2427-44.

26. Foster BA, Aquino CA, Gil M, Gelfond JA, Hale DE. A pilot study of parent mentors for early childhood obesity. J Obes 2016;2016:2609504.

27. Salvy SJ, de la Haye K, Galama T, Goran MI. Home visitation programs: an untapped opportunity for the delivery of early childhood obesity prevention. Obes Rev 2017;18:149-63.

28. Schwartz RP, Hamre R, Dietz WH, Wasserman RC, Slora EJ, Myers EF, et al. Office-based motivational interviewing to prevent childhood obesity: a feasibility study. Arch Pediatr Adolesc Med 2007;161:495-501.

29. Resnicow K, McMaster F, Bocian A, Harris D, Zhou Y, Snetselaar L, et al. Motivational interviewing and dietary counseling for obesity in primary care: an RCT. Pediatrics 2015;135:649-57.

30. He Q, Ding ZY, Fong DY, Karlberg J. Blood pressure is associated with body mass index in both normal and obese children. Hypertension 2000;36:165-70.

31. Williams CL, Strobino B, Bollella M, Brotanek J. Body size and cardiovascular risk factors in a preschool population. Prev Cardiol 2004;7:11621.

32. Olshansky SJ, Passaro DJ, Hershow RC, Layden J, Carnes BA, Brody J, et al. A potential decline in life expectancy in the United States in the 21st century. N Engl J Med 2005;352:1138-45. 


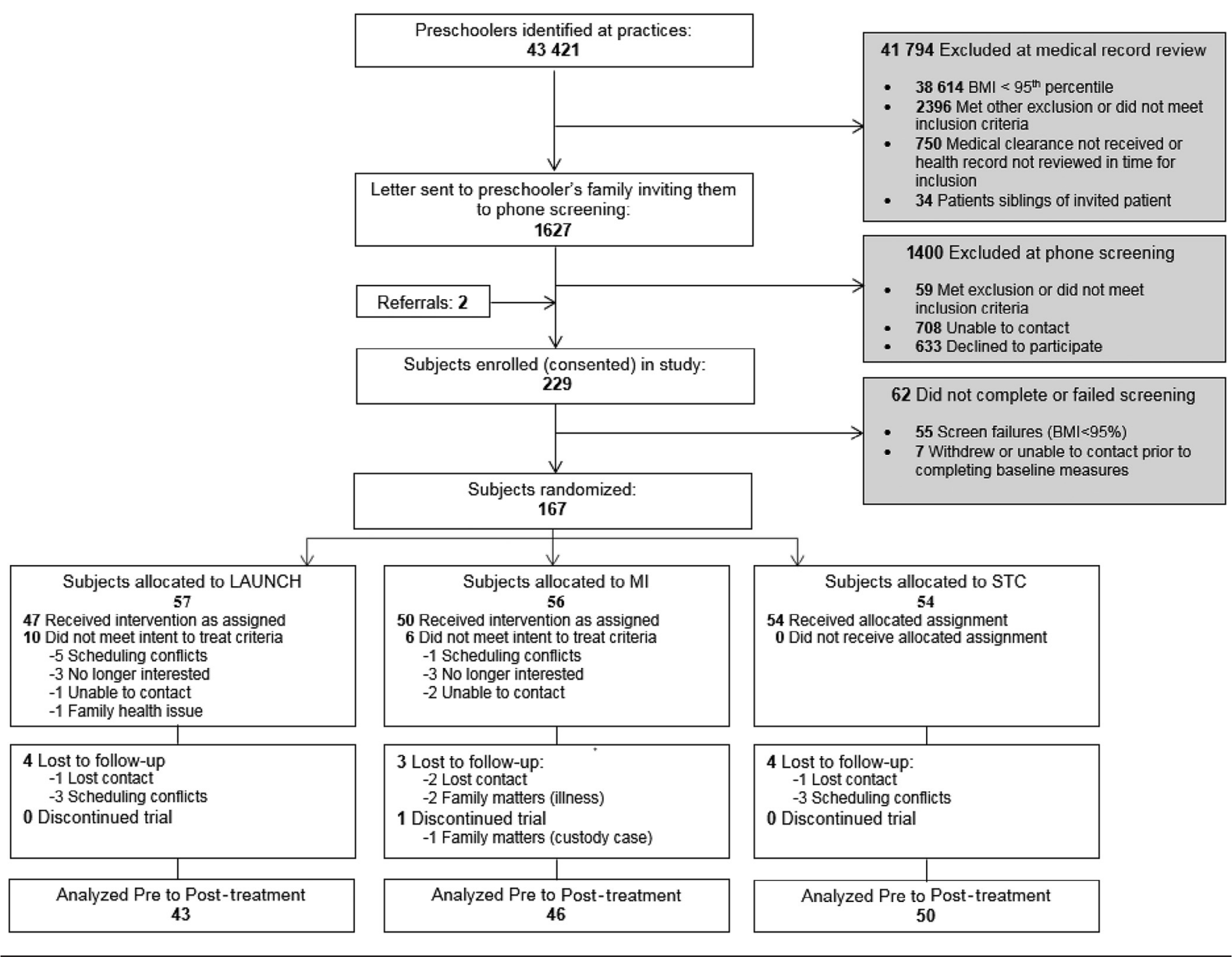

Figure 1. CONSORT flow diagram of participants to $\mathrm{LAUNCH}$, motivational interviewing, and standard care.

Table III. Weight, height, BMIz, BMI percentile for age and sex, and \%OBMI at baseline and 6 months and change scores over intervention period for LAUNCH, motivational interviewing, and standard care

\begin{tabular}{|c|c|c|c|c|c|c|c|c|c|}
\hline \multirow[b]{2}{*}{ Variables } & \multicolumn{3}{|c|}{$\begin{array}{l}\text { LAUNCH } \\
(n=43)\end{array}$} & \multicolumn{3}{|c|}{$\begin{array}{l}\text { Motivational interviewing } \\
\qquad(n=46)\end{array}$} & \multicolumn{3}{|c|}{$\begin{array}{c}\text { Standard care } \\
(n=50)\end{array}$} \\
\hline & Baseline & Mo 6 & Change & Baseline & Mo 6 & Change & Baseline & Mo 6 & Change \\
\hline Height & 111.10 (8.64) & 114.74 (8.38) & $3.64(0.90)$ & 111.96 (7.89) & $115.85(7.56)$ & $3.89(0.91)$ & 110.85 (7.94) & 114.64 (7.78) & $3.79(0.91)$ \\
\hline Weight & $26.04(6.10)$ & $26.71(6.18)$ & 0.67 (1.86) & $25.95(5.02)$ & $28.16(5.45)$ & $2.21(1.35)$ & $25.74(5.17)$ & $27.76(6.05)$ & 2.03 (1.75) \\
\hline BMlz & $2.40(0.54)$ & $2.08(0.62)$ & $-0.32(0.33)$ & $2.39(0.57)$ & $2.35(0.54)$ & $-0.05(0.27)$ & $2.44(0.64)$ & $2.31(0.63)$ & $-0.13(0.31)$ \\
\hline BMI percentile & 98.55 (1.25) & 96.56 (3.64) & $-2.00(2.91)$ & 98.45 (1.34) & $98.23(1.80)$ & $-0.21(1.23)$ & 98.52 (1.32) & $97.75(2.68)$ & $-0.77(1.94)$ \\
\hline \%OBMI & $34.87(17.10)$ & $30.43(17.80)$ & $-4.45(7.55)$ & $33.63(15.60)$ & 36.07 (16.72) & $2.43(5.62)$ & 34.88 (15.24) & 36.33 (17.83) & 1.45 (7.49) \\
\hline
\end{tabular}

